\title{
Perancangan Sistem Pembayaran SPP Pada SMK Islam Iqro Pasar Kemis
}

\author{
Yuni Roza* ${ }^{1}$, Nurlaila Suci Rahayu Rais ${ }^{2}$, Aditya Risdiarto Jati ${ }^{3}$ \\ ${ }^{1,2}$ Program Studi Manajemen Informatika Fakultas Sains dan Teknologi Universitas Raharja, \\ ${ }^{3}$ Program Studi Sistem Informasi Fakultas Sains dan Teknologi Universitas Raharja \\ E-mail : *1yuni.roza@ raharja.info, ${ }^{2}$ nurlaila@ raharja.info, ${ }^{3}$ risdiarto.jati@ raharja.info
}

\begin{abstract}
Abstrak
Sekolah Menengah Kejuruan (SMK) Islam Iqro Pasar kemis memiliki visi, misi dan tujuan mencetak lulusan yang beriman, bertaqwa serta berakhlak mulia juga kompeten dalam penguasaan IPTEK. Namun saat ini SMK Islam Iqro Pasar Kemis masih menggunakan cara konvensional dalam melakukan transaksi SPP yaitu staf keuangan menulis semua transaksi pada kartu siswa dan rekapitulasinya ditulis kembali pada sebuah buku sebagai bukti dari transaksi. Hal ini menyebabkan proses pembayaran membutuhkan waktu lama dan tingkat kesalahan yang besar, selain itu juga menghambat tingkat kecepatan akses data dan penyampaian informasi menjadi terlambat. Dengan permasalahan yang ada maka peneliti mengusulkan perancangan sistem pembayaran untuk memudahkan proses pembayaran SPP. Metode yang digunakan oleh penulis adalah analisis SWOT, untuk metode perancangan menggunakan Unified Modelling Language (UML), dan metode pengujian sistem menggunakan Blackbox Testing. Penelitian ini bertujuan untuk memudahkan dalam pelaksanaan kegiatan pembayaran SPP sekolah dan penyampaian informasi dari pihak sekolah yang ditujukan kepada siswa dan orang tua siswa.
\end{abstract}

Kata Kunci-Siswa, SPP, Pembayaran

\begin{abstract}
Islamic Vocational School Iqro Pasar kemis has the vision, mission and goals of graduates who have faith, piety and morality as well as competent in mastery of science and technology. But now Islamic vocational high school Iqro Pasar Kemis still use conventional way in conducting SPP transactions that is by noting the payment card and payment data manually recorded on the book. This causes the payment process to take a long time and a large errorrate, but it also inhibits the speed of data access and information delivery to be too late. With the existing problems then the researchers propose the design of payment systems to facilitate the process of payment of SPP. The research method used is SWOT analysis, for design method using Unified Modeling Language (UML), and system testing method using Blackbox Testing. This research is expected to provide easiness in the implementation of school fee payment activities as well as easiness in the delivery of school fee payment information to students and parents of students.
\end{abstract}

Keywords—Student, SPP, Transaction 


\section{PENDAHULUAN}

Sistem pembayaran sekolah atau yang sering dikenal dengan SPP adalah suatu transaksi keuangan yang dilakukan oleh siswa dengan tujuan untuk menunjang kegiatan pembinaan pendidikan di sekolah. Ketepatan, keakuratan, dan kecepatan dalam pembayaran merupakan faktor utama untuk menjaga kredibilitas sekolah serta dapat memperlancar pembiayaan kegiatan belajar mengajar, selain itu juga mendukung fasilitas sekolah. Untuk menciptakan ha-hal tersebut dibutuhkan sebuah sistem berbasis komputer agar sistem pembayaran sekolah tersebut lebih efektif dan efisien.

Komputer adalah sebuah piranti atau perangkat elektronik yang dapat mengolah data yang dapat membantu penyelesaian tugas-tugas tersebut. Perkembangan komputer saat ini salah satunya dibidang informasi sangat pesat dalam segala bidang dan khususnya dalam bidang pendidikan terutama administrasi keuangan. Perkembangan sistem informasi dapat membantu administrasi keuangan atau staf keuangan yang biasanya harus dilakukan secara manual dapat dipermudah dengan menggunakan komputer sehingga pekerjaan lebih efektif dan efisien.

\subsection{PERMASALAHAN}

Di SMK Islam Iqro Pasar Kemis layanan pembayaran masih dilakukan secara manual. Dengan cara menginput data pembayaran siswa, sehingga memerlukan waktu yang cukup lama, dan terkdang mengalami kesalahan saat melakukan pekerjaan tersebut. Dengan adanya komputer diharapkan sistem yang digunakan dalam melakukan pekerjaan terutama dalam menginput data pembayaran siswa dapat berjalan dengan cepat serta dapat menyimpan hasil yang telah diolah secara cepat dan tepat sehingga akan mudah mengakses kembali bila suatu saat nanti dibutuhkan. Dan juga untuk menjaga keamanan data itu sendiri.

\section{METODE PENELITIAN}

\section{1. $\quad$ Metode Pengumpulan Data}

1. Observasi (Observation Research)

2. Melakukan pengamatan secara langsung dan melaksanakan pencatatan secara sistematis terhadap unsur-unsur yang dianggap perlu dalam pengumpulan data hendaknya dikemukakan dan dijelaskan dalam laporan. Sifat dan tujuan penelitian, sifat dan wujud data yang hendaknya dikumpulkan di SMK Islam Iqro PasarKemis.

3. Wawancara (Interview Research)

4. Penulis juga melakukan wawancara terhadap orang-orang yang bersangkutan dengan proses pembayaran SPP di sekolah tersebut seperti, bagian keuangan dankasir.

5. Studi Pustaka

6. Pada kegiatan ini penulis melakukan untuk mendapatkan informasi yang dibutuhkan dengan mempelajari buku-buku yang sesuai dengan topik penelitian sebagai sumber tertulis yang memuat informasi.

\subsection{Metode Perancangan}

Menurut Imbar dan Hartono (2015:13)., "UML adalah bahasa spesifikasi standar untuk mendokumentasikan, menspesifikasikan, dan membangun sistem perangkat lunak". Pada penelitian ini metode yang digunakan adalah UML (Unified Modeling Language) diantaranya yang menggunakan Use Case Diagram, Class Diagram, Activity Diagram, Sequence Diagram. Dengan menggunakan software Visual Paradigm for UML 10.0. 


\subsection{Literature Review}

Menurut Mulyandi (2013:17-153), "Penelitian sebelumnya (Literature Review) merupakan survey literature tentang penemuan - penemuan yang dilakukan oleh peneliti sebelumnya (empirical finding)yang berhubungan dengan topik penelitian". Berikut penelitian yang telah dilakukan dan memiliki korelasi yang searah dengan penelitian yang akan dibahas, antara lain :

1. Penelitian ini dilakukan oleh Adhani, dkk pada tahun 2015 yang berjudul "Analisa Dan Perancangan Sistem Informasi Penerimaan Siswa Baru Dan Pembayaran Spp Menggunakan Zachman Framework". Penelitian ini menjelaskan bahwa Saat ini proses penerimaan siswa baru dan pembayaran Surat Perintah Pembayaran (SPP) dilakukan dengan metode konvensional yatiu proses seleksi dilakukan dengan cara referensi dari sekolah menengah pertama dimana siswa langsung diterimatanpa melalui tes baik tess tulis maupun tes lainnya. Pembayarandilakukansecarabergilirdan seringkali melebihi limit waktu yang ditentukan dikarenakan tidak adanya sistem yang mampu membantu proses penerimaan dan pembayaran pada sekolahtersebut.

2. Penelitian ini dilakukan oleh Anggit Susanto pada tahun 2016 yang berjudul "Perancangan Aplikasi Pembayaran Spp Pada Sma Negeri 1 Ambarawa Menggunakan Bahasa Pemrograman Visual Basic 6.0". Penelitian ini menjelaskan bahwa SMA Negeri 1 Ambarawa adalah institusi pendidikan yang selalu ingin mengikuti perkembangan teknologi informasi yang sedang berkembang. Bagian administrasi keuangan atau staf keuangan masih mengalami kesulitan dalam proses pengerjaannya karena sistem yang digunakan masih manual. Sehingga informasi yang dihasilkan belum sesuai dengan yang tujuan yang diharapkan, seperti keakuratan dalam pengolahan data dan pembuatan laporan. Dalam hal ini dibutuhkan keefektifan dan keefisienan dalam penginputan, pemrosesan dan pengolahan data hingga pembuatan laporan.Hal ini disebabkan terbatasnya sumber daya manusia dan banyaknya data yang dikelola. Dalam hal ini tentunya proses pengolahan harus diolah secara efektif, efisien dan proses pengolahan data yang dijalankan harus mudah dalam pengisian data, pemrosesan data dan pelaporannya. Sedangkan ditinjau dari keefektifan sebuah sistem baik dari segi manfaat, biaya, maupun waktu yang digunakan, kesemuanya itu harus dapat mendukung tercapainya pemenuhan akan informasi pengolahan data yangberkualitas.

3. Penelitian ini dilakukan oleh Sudirman, dkk pada tahun 2012 yang berjudul "Perancangan Program Aplikasi Transaksi Pembayaran SPP, UTS dan UAS Menggunakan Metode Analisis dan Desain Berorientasi Objek Model Unified Approach (UA)" . Penelitian ini membahas Program Aplikasi Transaksi Pembayaran SPP yang ada di SMK Muhammadiyah Garut, sebagai sarana untuk pendukung aktivitas transaksi pembayaran di bagian Tata Usaha Sekolah. Dengan meningkatnya jumlah siswa yang ada pada SMK Muhammadiyah Garut, mengalami kendala menghadapi siswa yang melakukan pembayaran SPP dengan proses manual, dan mengakibatkan pencatatan, penyimpanan data pada transaksi pembayaran SPP disimpan dalam bentuk manual yang ditulis pada buku-buku besar, sehingga petugas mengalami kesulitan dalam pencarian informasi data siswa yang sudah atau belum melakukan pembayaran, dan petugas kesulitan dalam pembuatan laporan yang tepat dan akurat. Dengan kronologi dan permasalahan yang dihadapi di atas, penulis membuat sebuah sistem informasi untuk transaksi untuk pembayaran SPP, UTS dan UAS. Penelitian ini menggunakan metode analisa dan pengembangan sistem yang digunakan metodologi berorientasi objek yaitu Unified Approach (UA) dikemukakan oleh Ali Bahrami (1999) yang terdiri dari tahapan-tahapan Object Oriented Analysis (OOA) dan Object Oriented Design (OOD) dengan menggunakan notasi grafis standar Unified Modelling Language (UML) untuk memodelkan kebutuhan sistemnya. Berdasarkan analisa dan perancangan sistem informasi pembayaran SPP, UTS dan UAS di SMK Muhammadiyah Garut, 
mampu menghasilkan sebuah aplikasi yang bertujuan untuk meningkatkan produktivitas dan menunjang fasilitas dalam aktivitas administrasi keuangan khususnya pembayaran SPP, UTS dan UAS di SMK Muhammadiyah Garut

4. Penelitian ini dilakukan oleh Fristanto, dkk pada tahun 2014 dengan judul "Rancang Bangun Sistem Informasi Pembayaran Sumbangan Pembinaan Pendidikan (SPP) dan Insidental Pada Sekolah Menengah Kejuruan Muhammadiyah Tinatar Punung". Penelitian ini menjelaskan tentang bagaimana sistem yang berjalan mulai dari proses pendataan siswa hingga pembayaran keuangan siswa ini masih kurang efektif dan kurang efisien dimana dalam pencatatan terutama dalam pembayaran SPP dan Insidental dilakukan secara berulang-ulang sehingga menyebabkan proses yang lama pada pengolahan data dan membutuhkan waktu yang relative lama, terutama untuk menentukan sebuah keputusan dalam menindaklanjuti informasi yang didapat dari siswa. Pembayaran SPP dan insidental di SMK muhammadiyah Tinatar Punung masih konvensional dan belum memiliki sistem yang berbasis komputer. Dengan dibuatnya sebuah sistem informasi untuk pembayaran SPP dan insidental siswa pada SMK Muhammadiyah Tinatar punung, Pengelolaan data pembayaran menjadi lebih mudah dan akurat, karena pengelolaan pembayaran menggunakan sistem berbasis komputer.

5. Penelitian ini dilakukan oleh Sari dan Lidya pada tahun 2017 yang berjudul "Mobile Application Reminder of SPP Payment Schedule and School Activities Information Based SMS Gateway". Penelitian ini menjelaskan bahwa untuk membangun informasi fasilitas Jadwal Pembayaran dan Penyebaran SPP Kegiatan Informasi di TK Alfaduta Dumai. Ini aplikasi mampu menangani proses pembayaran dan menyampaikan Kegiatan informasi lebih efisien menggunakan informasi teknologi. Aplikasi ini akan membantu penyebarannya informasi dengan cepat dan mengurangi keterlambatan pembayaran informasi dengan menggunakan fasilitas SMS (Short Message Service) Gateway untuk orang tua / wali. Aplikasi ini menggunakan SMS Gateway yang bisa menyebarkan pesan ke pengguna otomatis dan cepat. Ini terhubung langsung dengan database nomor ponsel dan operator tidak harus mengetikkan ratusan angka dan pesan di ponsel telepon, karena semua nomor akan diambil secara otomatis dari database. Mekanisme ini memungkinkan semua jenis pengumuman dikirim melalui SMS menggunakan Mobile Application Reminder Payment Jadwalkan Informasi Kegiatan SPP dan Sekolah. SMS itu Gateway akan bisa memudahkan administrator dan sekolah untuk memberikan berbagai informasi kepada orang tua atau wali, dan mengatasi keterlambatan pembayaran SPP setiap bulan.

\section{HASIL DAN PEMBAHASAN}

Rancangan sistem ini menggunakan Visual Paradigm for UML 10.0, salah satu nya menggambarkan sequence diagram. 


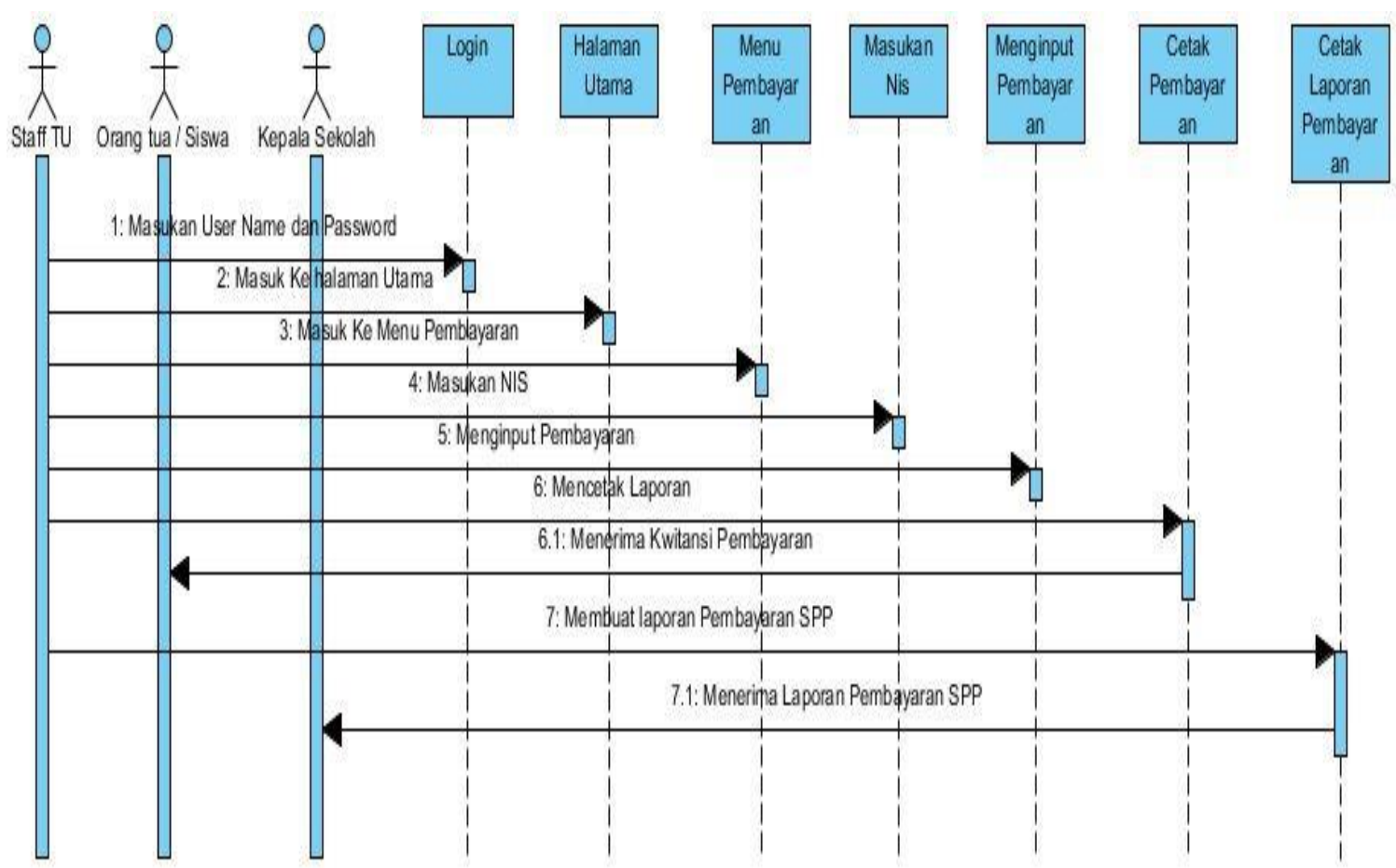

Gambar 1. Sequence Diagram

Berdasarkan gambar sequence diagram diatas dapat dilihat bahwa terdapat:

1. 3 (tiga) Actor yang melakukankegiatan.

2. $\quad 7$ (tujuh) Life Line objek entity antar muka yang salingberinteraksi.

3. 9 (sembilan) Message spesifikasi dari komunikasi antar objek yang membuat informasiinformasi aktivitas yang terjadi.

Di bawah ini merupakan gambar tampilan rancangan yang dibuat :

\subsection{Tampilan Login}

\section{APLIKASI \\ PEMBAYARAN SPP}

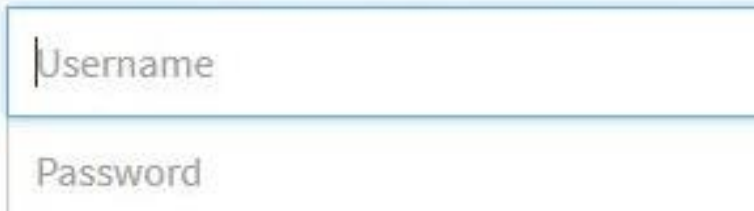

\section{Login}

Gambar 2. Tampilan Login 
Gambar 2 merupakan tampilan halaman login pada saat admin akses ke sistem. Halaman ini berfungsi untuk secure agar tidak semua orang dapat mengaksesnya. Pada menu login ini yang bisa login hanya admin atau yang bersangkutan.

\subsection{Tampilan Dashboard}

USPP Home Pembayaran Laporan T Datallaster r

\section{APLIKAS PEMBAYARAN SPP SUKISLAM IQPOPASSRR KEMIS}

\section{Selamat Datang Gasir}

Gambar 3. Tampilan Dashboard

Gambar 3 merupakan halaman utama yang menyajikan menu-menu yang dapat diakses, dimana halaman ini muncul setelah admin berhasil memasukkan username dan password pada saat login.

\subsection{Tampilan Data Pembayaran SPP}

\section{Pembayaran SPP}

Nomor Induk Siswa

Nomor Induk Siswa

Gambar 4. Tampilan Data Pembayaran SPP

Gambar 4 merupakan halaman pembayaran SPP yang menampilkan pencarian berdasarkan nomor induksiswa. 
ISSN: 2356-5209

\subsection{Tampilan Data Siswa}

\section{Daftar Siswa}

\begin{tabular}{|c|c|c|c|c|}
\hline$\#$ & NIS & Nama Lengkap & Prodi & Tambah Data \\
\hline 1 & 2014201501 & MUHAMMAD ALDIN IRFANI & & Edit Hapus \\
\hline 2 & 2014201502 & ROZZY ALAMSYAH SUKMA SAEFUDIN & & Edit Hapus \\
\hline 3 & 2014201503 & DIMAS SAWONG LAGA & & Edit Hapus \\
\hline 4 & 2014201504 & DEDY KURNAAWAN EFENDI & & Edit Hapus \\
\hline 5 & 2014201505 & MUHAMMAD FAJAR & & \begin{tabular}{l|l} 
Edit & Hapus
\end{tabular} \\
\hline 6 & 2014201506 & ARIEF MAHPUTRA ARDIANSYAH & & Edit Hapus \\
\hline
\end{tabular}

Gambar 5. Tampilan Data Siswa

Gambar 5 merupakan halaman pengolahan data siswa yang menampilkan data dari setiap siswa.

\subsection{Tampilan Data Jurusan}

\section{Daftar Program Studi}

\begin{tabular}{|l|l|l|l|}
\hline \# & Kode Prodi & Program Studi & Tambah Data \\
\hline 1 & MIF & Nanajemen Informatika & Edit Hapus \\
\hline 2 & TIP & Teknologi Industri Pangan & Edit Hapus \\
\hline 3 & TKJ & Teknik Komputer Jaringan & Edit Hapus \\
\hline
\end{tabular}

Gambar 6. Tampilan Data Jurusan

Gambar 6 merupakan halaman pengolahan data siswa yang menampilkan data setiap jurusan siswa. 


\section{KESIMPULAN}

Berdasarkan hasil penelitian dan observasi yang dilakukan penulis pada sistem pembayaran SPP pada SMK Islam Iqro Pasar Kemis maka penulis menarik kesimpulan sebagai berikut :

1. Sebelumnya sistem informasi mengenai perihal pembayaran spp belum ada, karena sistem yang berjalan saat ini masih secara manual. Pada pelayanan pembayaran SPP tersebut, staff hanya dapat melakukan pencatatan pada buku, sehingga data yang dimasukkan sewaktu-waktu dapat hilang maupun rusak. Dengan adanya sistem yang peneliti rancang, staff dapat melakukan input data secara terkomputerisasi pada sistem pembayaranSPP.

2. Proses pembayaran SPP pada SMK Islam Iqro Pasar kemis masih belum efektif dikarenakan dalam kegiatan transaksi masih secara manual dengan mencatat dalam buku transaksi serta masih sulit dalam merekap data pembayaran untuk pembuatan laporan sehingga membutuhkan waktu yang lama dalam pembuatan laporan pembayaran SPP siswa.

3. Membuat sistem terkomputerisasi dengan menggunakan bahasa Pemrograman PHP dan MySQL untuk pembuatan database nya serta perancangannya menggunakan Unified Modelling language dan untuk kata kunci dalam pembayaran menggunakan NIS (Nomor Induk Siswa). Adapun tampilan yang terdapat dalam sistem yaitu menu pembayaran, laporan, serta data master . Hal ini sesuai dengan kebutuhan pembayaran SPP pada SMK Islam Iqro Pasar kemis.

\section{SARAN}

Berdasarkan hasil penelitian dan analisis yang dilakukan oleh penulis mengenai sistem pembayaran SPP pada SMK Islam Iqro Pasar Kemis, maka terdapat beberapa rekomendasi yang dapat dijadikan masukkan untuk meningkatkan kinerja, yaitu sebagai berikut:

1. Untuk memaksimalkan pemanfaatan sistem yang dibuat maka dapat dilakukan pelatihan bagi staf TU agar lebih memahami sistem yangada.

2. Diperlukan back up data secara berkala dan perawatan untuk menghindari terjadinya kehilangan atau kerusakandata.

3. Dilakukan pengembangan sistem yang baru untuk mengikuti perkembangan teknologi dimasa mendatang.

\section{DAFTAR PUSTAKA}

[1] Imbar, R. V., \& Hartanto, B. S. 2015. 10. Aplikasi Sistem Informasi Sumber Daya Manusia dengan Fitur DSS Menggunakan Metode Topsis pada PT. X. Jurnal Informatika,7(2).

[2] Mulyandi, Muhammad Rachman, Monica, Ega Mawarni, Arfiah dan Liya Jayanti. 2013. Aplikasi Sistem Informasi Laporan Penggajian Guru Honor Berbasis Web pada SMA Negeri 6 Tangerang. Yogyakarta: Prosiding Seminar Nasional Teknologi Informasi dan Multimedia (Semnas teknomedia) 2013. STMIK AMIKOM Yogyakarta 19 Januari2013.

[3] Adhani, M., Abdillah, L. A., \& Widayati, Q. 2015, August. Analisa dan perancangan sistem informasi penerimaan siswa baru dan pembayaran SPP menggunakan Zachman Framework. In Seminar Nasional Informatika 2015 (SNIf2015). Universitas Potensi 
Utama

[4] Susanto, A. 2016. PERANCANGAN APLIKASI PEMBAYARAN SPP PADA SMA N 1 AMBARAWA MENGGUNAKAN BAHASA PEMROGRAMAN VISUAL BASIC 6.0. PROCEEDING KNSI,4(1).

[5] Sudirman, H., Retnadi, E., \& Kurniawati, R. 2012. Perancangan Program Aplikasi Transaksi Pembayaran Spp, Uts Dan Uas Menggunakan Metode Analisis Dan Desain Berorientasi Objek Model Unified Approach (Ua). Jurnal Algoritma,9(01).

[6] Fristanto, H. T., Purnama, B. E., \& Sukadi, S. 2014. Rancang Bangun Sistem Informasi Pembayaran Sumbangan Pembinaan Pendidikan (SPP) Dan Insidental Pada Sekolah Menengah Kejuruan Muhammadiyah Tinatar Punung. Jurnal Teknologi Informasi dan Komunikasi, 5(1),63-67.

[7] Sari,F.,\&Lidya,P. 2017. Mobile Application Reminder Of SPP Payment Schedule's And School Activities Information Based SMS Gateway. Journal of Telecommunication, Electronic and Computer Engineering (JTEC), 9(3-8), 27-31. 